\title{
Geographic information systems for integrated coastal management and development of sustainability indicators
}

\author{
J. L. Almazán Gárate \& the Maritime and Portuary Engineering \\ Investigation Group \\ Polytechnic University of Madrid, Spain
}

\begin{abstract}
The anthropic pressure on the coastal zone in countries such as Spain make it necessary to carry out adequate performances in planning, as well as management and administration, to achieve an optimal sustainable development. In such a fragile zone with adequate complex information strategies, to achieve that objective requires full data integration from different areas of knowledge, which is the main purpose of the research project titled "Development of new technologies of physical modelization and tools for its use for Integral Coastal Management in Spain" developed by the authors.

The main goals set for this research project are the development and optimization of an integrated system to carry out successive high precision bathymetries; integration of results measured through a period of time on a coastal stretch using computerized coastal dynamics mathematical models; design of a geographic information system to integrate information needed to back the decisions for an optimal Integrated Coastal Management; determination of criteria to identify and quantify the alternatives proposed as coastal interventions when needed and development of sustainability indicators comprising socioeconomic, geographic and environmental aspects, to evaluate and follow up consequences of decisions adopted.

The research project is divided into two phases. The first of these is focused on the description of an application for satellite positioning and computerized methods for high precision bathymetries and its applications to coastal dynamics mathematical models and the incorporation of all data to the Geographic Information System. The second phase is focused on setting up the criteria for the identification and quantification of indicators for the interventions considered
\end{abstract}


for a particular coastal zone. The sustainability indicators comprise socioeconomic, geographic and environmental aspects, making it possible to evaluate jointly the interventions and their effects on coastal dynamics in an integrated way.

Keywords: geographic information system, survey, bathymetry, indicators.

\section{Introduction}

As far as economy is concerned, the tourism industry has a significant weight, and this weight is even more significant concerning Spanish coasts and all the leisure activities associated with them. Internal migrations to the coast in Spain have created a strong anthropic pressure on the coastal zone, aggravating those problems associated with seasonal tourism.

Despite efforts from public service organizations to develop non coastal tourism, which is already having pretty good results, the increase in population and tourism keeps creating pressure on the rather fragile coastal zone. Beaches are the main destination for tourism, and are defined as coastal features formed by sediments that are deposited and that were conducted by rivers to the sea.

The lack of water and main rivers water regulation, along with desirable measures against flooding, have resulted in a lack of sediments in the Mediterranean and South Atlantic coasts (Cádiz and Huelva), and that has produced erosions in many popular beaches in Spain. Considering concepts, a coastal feature formed by sediments in erosion is transformed into an erosion landform.

Global warming processes that are being experimented on our planet, associated with a slow water level increase, have contributed to the erosion processes in zones with low tectonic activity.

These processes can be regarded as slow processes, but if we consider a four year spell in between elections in Spain, those processes are significant in terms of usual business and are vertiginously fast using a geological scale $[1,2]$.

Erosion processes can be modified by civil engineering actions that require inversions, and resources assignments should be related to objective parameters to ease decision making processes, having currently enough technical tools to analyze this problem from three different points of view:

A. Litoral behaviour knowledge against environmental actions, mainly waves and currents.

B. Quantification for costs of execution of those civil engineering actions necessary to modify undesirable behaviours from natural elements appointed to be preserved.

C. Financial evaluation and estimation for profitability both in financial and economic terms, considering all the aspects regarding environmental accounting as well as social aspects associated with actions to take place in a coastal zone in a country like Spain.

Spain is well portrayed by its coastal length and also by the importance that the coast has in its economy regarding tourism and how its management can be 
decisive on the environment and also in eco-systems sustainability in the coastal zone and continental shelf. In this sense it is necessary to analyze such a great coastal system after the natural and human actions. Also, coastal management should consider global changes, e.g. water level increase and climate change [3].

One of the main objectives for coastal engineering is how to modelize a coastal zone and all the processes acting on that particular zone, i.e., from an initial state, make predictions with enough precision and accuracy through a period of time. Nowadays there are many models that fulfil those tasks. On the other hand, computer rising makes it possible to improve those models. However, bathymetry methods are not precise nor accurate enough for the most advanced models. That makes those advanced models useless $[4,5]$.

The project that is being introduced in these paragraphs is expected to apply the latest satellite positioning techniques and computer methods to obtain high precision bathymetries and use them in beach evolution models. It is also expected to develop a new bathymetric system that is able to get more than 10,000 bathymetric points per hour with centimetric precision [6-8].

The main goals set for this research project are the following:

- Development and optimization of an integrated system to carry out successive high precision bathymetries.

- Integration of results measured through a period of time on a coastal stretch using computerized coastal dynamics mathematical models.

- Design of a geographic information system to integrate information needed to back the decisions for an optimal Integrated Coastal Management.

- Determination of criteria to identify and quantify the alternatives proposed as coastal interventions when needed.

- Development of sustainability indicators comprising socioeconomic, geographic and environmental aspects, to evaluate and follow up consequences of decisions adopted.

\section{Description of the location researched}

The physiographic region analysed includes the municipalities of Chipiona and Rota, with a total area of $117.2 \mathrm{~km}^{2}$ and a total population of 45753 [9].

The following beaches were surveyed:

- Regla beach: this is an urban fine sand beach, with moderate waves, a high occupation level and a length of about 1700 meters. It is considered the most emblematic beach in Chipiona.

- La Ballena beach: this is an urban fine sand beach, with light waves, a high occupation level and has a length of about 4500 meters.

- La Costilla beach: this is an urban fine sand beach, with light waves, a high occupation level and has a length of about 2200 meters. It is considered as one of the best beaches in Spain, and it is located to the west of Rota Port. 
- El Rompidillo beach: this is an urban fine sand beach, with light waves, a high occupation level and has a length of about 1500 meters. It is located in a sheltered zone, eastwards of Rota Port.

\section{Methodology}

Each of the beaches briefly introduced above was surveyed twice in a year in order to calculate sand accumulations and erosions through a direct comparison between the surfaces obtained in the surveys, as well as summer and winter profiles for these beaches due to seasonal alternation between dead calms and storms.

Additionally comparisons with data from surveys made a year before were made to evaluate the long term evolution undergone by the beaches. Those data used for the long term comparisons come from surveys made by the local coastal demarcation of Andalucía-Atlántico.

The methodology used to carry out bathymetries can be explained through the following steps [11]:

1. Data compilation: terrestrial cartography compilation from the Spanish Army Geographic Service and the National Geographic Institute. Data compilation on geodetic vertexes from the National Geodetic Network for the zone surveyed. Nautical charts and maritime climate compilation were also use as a complement for the data already compiled.

2. Reference stations location election for each of the beaches surveyed, as well as the link with the vertexes from the National Geodetic Network and the vertex located next to La Ballena beach.

3. Device calibration for the surveyed zone.

4. Survey execution for summer and winter campaigns.

5. Data integration.

6. Map designing and drawing using suitable software.

7. Database design.

8. Product generation.

\section{Geographic information system design}

All the data aforementioned were broken down in order to include them in a geographic information system. In order to achieve this it was necessary to validate and transform all data in a compatible version for the software used. The activities were carried out following the steps described as follows:

1. Base map display showing all four beaches surveyed: Base map conversion from AutoCad to a format compatible with ArcView. All reference bases were also included in the map.

2. Data integration for all 140 sample points: All the data from the samples analysis were integrated in tables associated to maps. Those data included profile number, depth, $\mathrm{D}_{50}$, etc. 


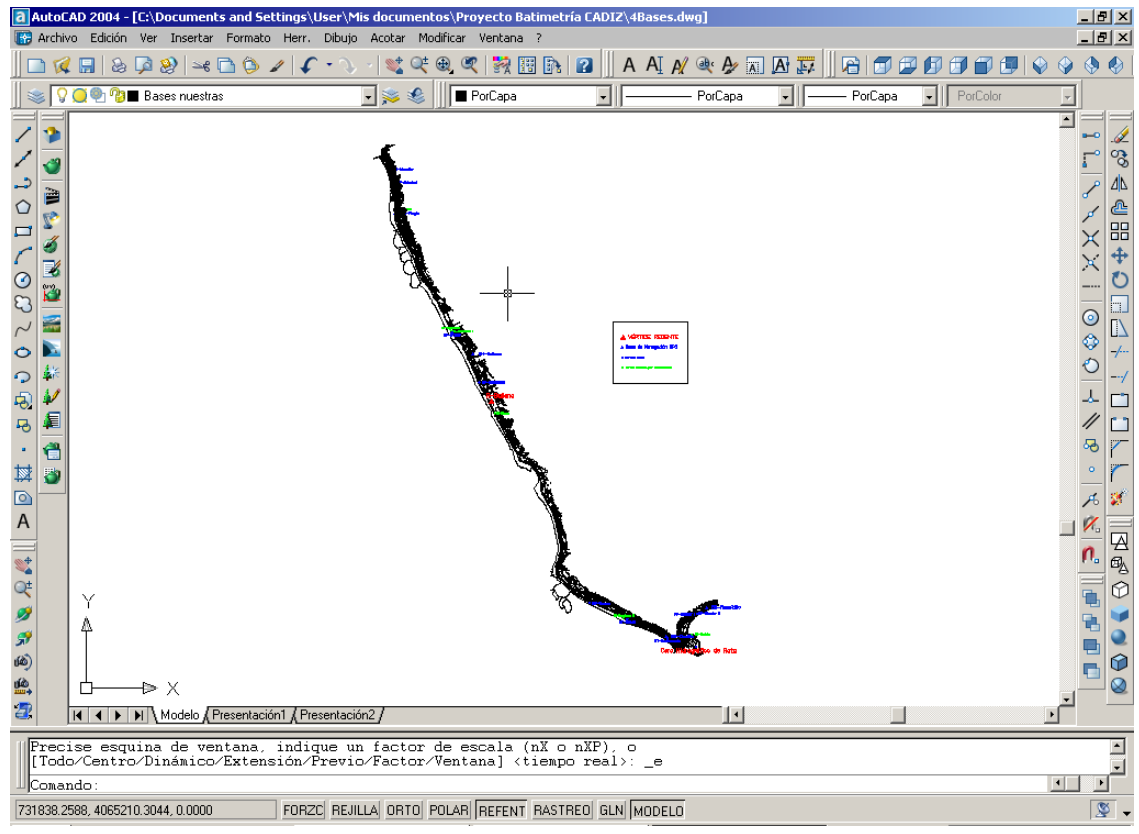

Figure 1: AutoCad map.

3. Echo sounder data conversion: All data was converted into an ArcView compatible format. In order to carry out that conversion it was necessary to maintain the coordinate references and so all points are completely arranged with an $\mathrm{x}, \mathrm{y}, \mathrm{z}$ trio.

4. Bathymetry lines incorporation with their respective labels: All data obtained in AutoCad format was converted into an ArcView compatible format and it was necessary to process each of the points surveyed.

5. Comparison between bathymetries corresponding to both winter and summer campaigns.

6. Profile drawing for each of the four beaches surveyed: Each of the profiles were drawn associated to an ArcView profile in another layer.

7. 3D models for each of the beaches surveyed: Each of the 3D models drawn were added to a layer associated with each of the beaches surveyed. It is important to consider that $3 \mathrm{D}$ models were made from data taken following lines perpendicular to the coast line with an equidistance of 100 meters, making the data density different between data parallel to the coast line and those that are perpendicular, making the model much more liable on the zones near the profile lines.

8. Integration of bathymetry comparisons: As there are seasonal variations between beach profiles in winter and summer, which are even more noticeable after severe storms, beach profiles adopt characteristic shapes recognizable in the bathymetries, experiencing severe erosion in the emerged zone and those sediments are accommodated in the zone 
affected by coastal dynamics. Those zones are not well defined when there are remarkable tides and that is the particular case of the zone surveyed with tide range of about 3.5 meters. It is noticeable that if there is sediment transport along the coast summer profiles are never recovered, so there is irreversible erosion. So it is useful to know the extent of these phenomena and it is necessary to make an in-depth study on the existing currents and sediment transport in potential and real cases.

\section{Results}

In this first phase of the Project the geographic information system is a useful tool that makes it possible to have all the information from the surveys incorporated into a system that is easy to operate, simplifying the design and obtaining the products needed by the user. Each of the elements added to the GIS has geographical references. Among those we find all sediment samples taken during the two bathymetric campaigns, along with the information table, such as the one shown in table 1.

Other elements added to the system are both summer and winter bathymetry maps, which can also be overlaid to obtain the difference between both bathymetries.

The profiles for each beach were also drawn, geo-referenced and associated to an image that represents the profile.

Table 1: $\quad$ Table showing D50 data from all samples.

\begin{tabular}{|c|c|c|c|c|c|c|c|c|}
\hline \multicolumn{2}{|c|}{ Sample Location } & \multicolumn{7}{|c|}{ Depth } \\
\hline Beach & Profile No. & 4 & 2 & 0 & -1 & -2 & -3 & -5 \\
\hline \multirow{5}{*}{ REGLA } & 2 & 0.32 & 0.36 & 0.72 & Rock & Rock & Rock & $*$ \\
\hline & 8 & 0.27 & 0.21 & 0.82 & 0.29 & 0.10 & 0.37 & Rock \\
\hline & 13 & 0.32 & 0.25 & 0.25 & 0.14 & 0.18 & Rock & Rock \\
\hline & 16 & 0.17 & 0.17 & 0.18 & 0.17 & Rock & Rock & Rock \\
\hline & 18 & 0.27 & 0.17 & 0.18 & Rock & Rock & Rock & Rock \\
\hline \multirow{5}{*}{ BALLENA } & 8 & 0.20 & 0.21 & Rock & Rock & 0.42 & 0.17 & Rock \\
\hline & 16 & 0.35 & 0.22 & 0.24 & 0.28 & 0.16 & 0.15 & 0.16 \\
\hline & 22 & 0.32 & 0.22 & 0.28 & 0.40 & 0.15 & 0.16 & 0.09 \\
\hline & 30 & 0.36 & 0.51 & 0.32 & 0.34 & Rock & 0.14 & Rock \\
\hline & 36 & 0.16 & 0.36 & 0.28 & 0.22 & Rock & 0.32 & 0.31 \\
\hline \multirow{5}{*}{ COSTILLA } & 2 & 0.18 & 0.34 & 0.29 & 0.56 & Rock & Rock & Rock \\
\hline & 6 & 0.32 & 0.33 & 0.54 & 0.36 & 0.45 & Rock & Rock \\
\hline & 12 & 0.22 & 0.32 & 0.31 & 0.37 & 0.31 & Rock & Rock \\
\hline & 16 & 0.23 & 0.51 & 0.33 & 0.20 & Rock & Rock & Rock \\
\hline & 24 & 0.30 & 0.27 & 0.90 & 0.23 & Rock & Rock & Rock \\
\hline \multirow{5}{*}{ ROMPIDILLO } & 2 & 0.25 & 0.10 & 0.25 & 0.38 & 0.30 & 0.25 & Rock \\
\hline & 4 & 0.32 & 0.16 & 0.13 & 0.28 & Rock & Rock & Rock \\
\hline & 6 & Rock & 0.23 & 0.17 & 0.29 & Rock & Rock & Rock \\
\hline & 9 & 0.23 & 0.76 & Rock & 0.12 & 0.18 & Rock & Rock \\
\hline & 12 & 0.25 & 0.30 & 0.22 & 0.13 & 0.18 & 0.15 & Rock \\
\hline
\end{tabular}

* Not enough depth 


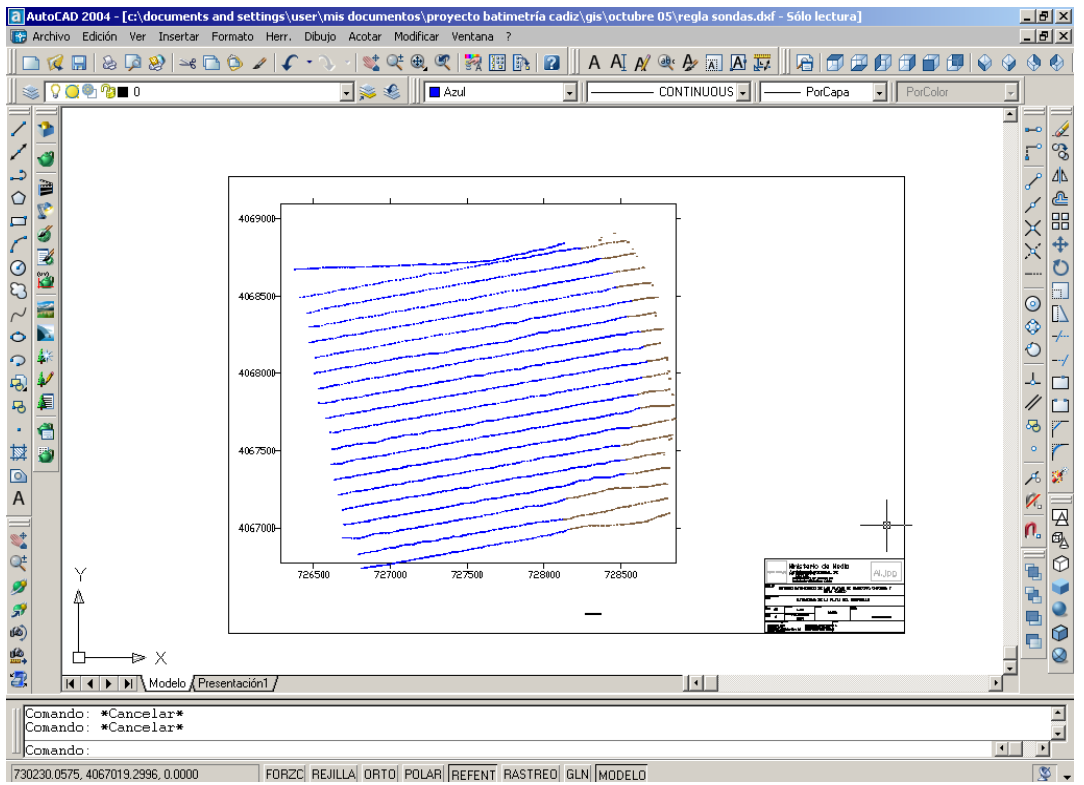

Figure 2: Bathymetry example using AutoCad.

On the other hand, more products can also be obtained depending on the information needed by the user. In this particular case two of those multiple products are shown, and these are the layer layout selected by the user and the printed report for all data previously selected.

\section{Development of sustainability indicators}

Given the fragility of the ecosystems present in the coastal zone surveyed, the importance derived from its legal nature justifies the diverse attempts to provide instruments and orientations for the integral coastal management in the European Union [11].

The interest and the necessity for sustainable development, the current concerns being faced that threaten the environment and the defective management carried out lately have also led to a re-examination of the means at our disposal to evaluate and monitor the evolution and trends of the environment, as well as those of the use of natural resources and development processes (Winograd [12]; EU [13]; Backhaus [14]).

The decision making process along with the analysis and monitoring of policies and development strategies often uses data, statistical economic and social indicators at regional and national level (UNEP [15]; UNDP [16]). However, regarding the environment, the equivalent information is not available to the user and frequently it does not even exist, preventing decision making regarding the environment from being carried out unless it considers components and characteristics from real processes. So it is necessary to provide the 


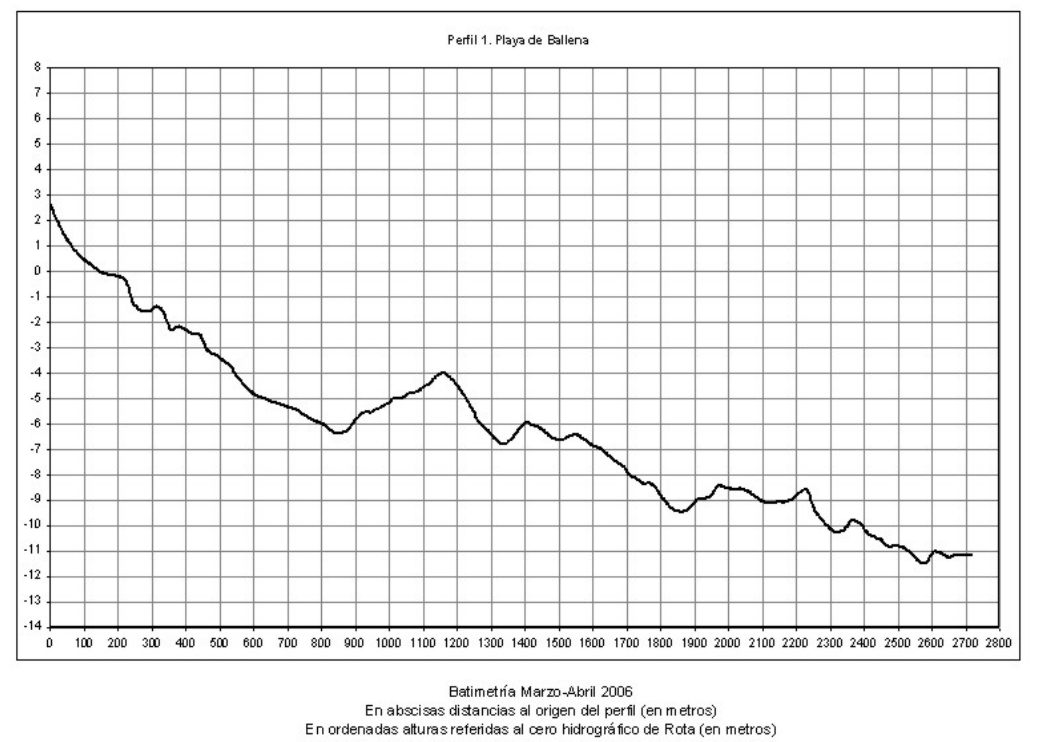

Figure 3: Profile example.

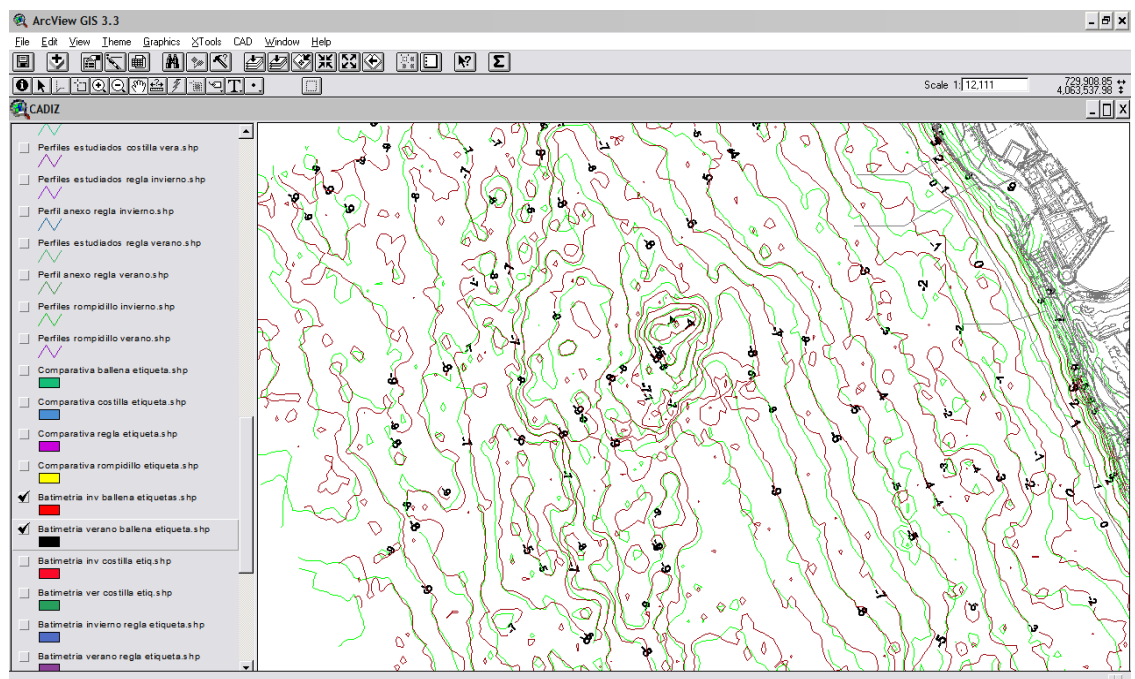

Figure 4: Comparison between winter and summer bathymetries. 


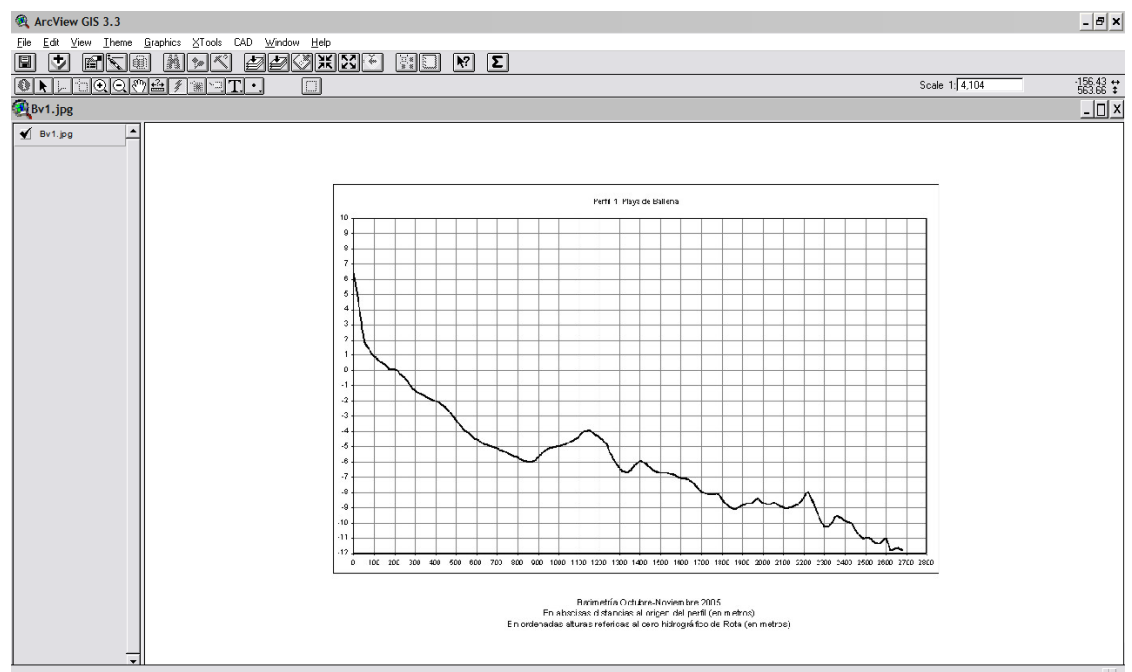

Figure 5: $\quad$ Example of profile.

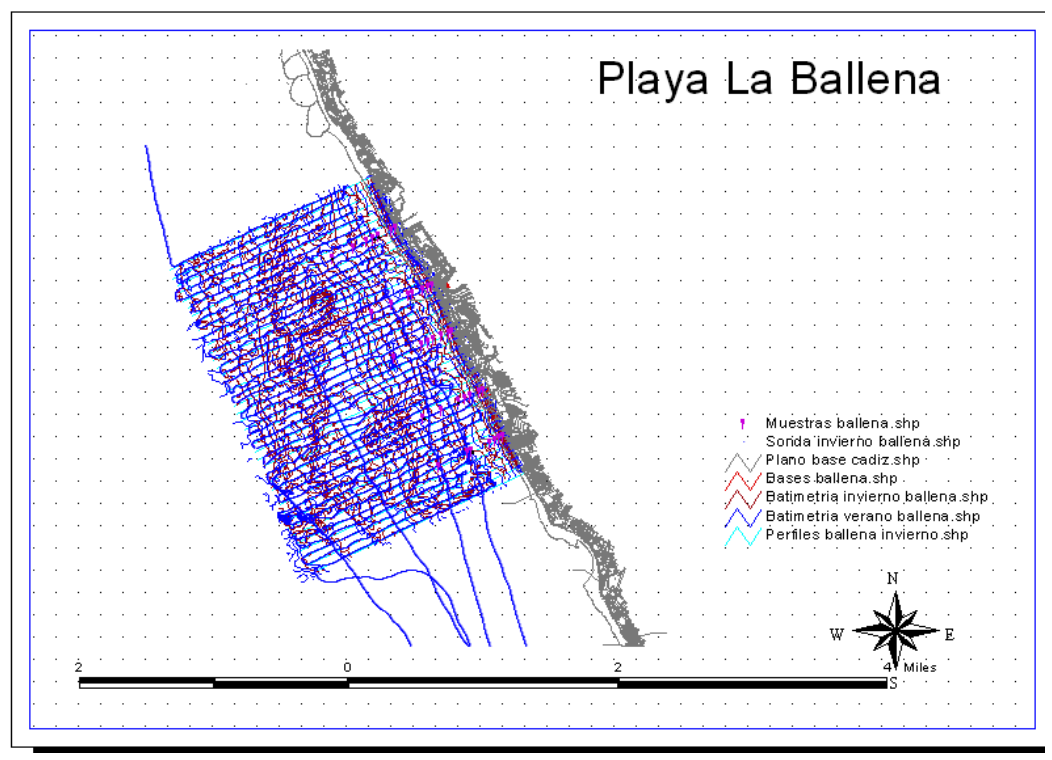

Figure 6: Example of layer layout. 
indicators needed to create an important tool in terms of communication, making scientific and technical information available to many groups of users (Lindsey et al. 1977).

In order to make a correct evaluation of the actions proposed and to check the consequences of those actions it is necessary to have a coherent measurement and evaluation system according to the characteristics of the zone surveyed. That is why it is necessary to have the appropriate indicators to form an evaluation and control tool for the environmental improvements carried out in the zone, along with the quality of life adapted to specific necessities of each region and social and economic development model.

The coastal zone integral management has been recognized as a sub-field of environmental planning. It incorporates several sectors and gathers regional relevance, given the growing importance of the coastal section in terms of healthy feeding, decrease of poverty, biodiversity conservation, and reduction of natural risks as well as economic development (Lowry 2002). Consequently, all those actions carried out in the coastal zone have to consider the economic, social and environmental realities. Given the information complexity it is necessary to have tools that simplify the decision making.

In this sense, the development of sustainability indicators makes it possible to consider the criteria that integrate the three spheres of action (economic, social and environmental), which are also integrated into the geographic information system, making it possible to update and look up any information on the indicators in a quantity and quality way.

From a methodological point of view it is useful to make a diagnosis to achieve the physiographic unit fragmentation in order to evaluate the current state of every segment, establishing each of the characteristics in common and the differences and interrelations that they have between them. This analysis is to establish possible guidelines to follow from the actions to be carried out for each coastal zone considered.

\section{Conclusion}

Geographic information systems are useful tools when managing great quantities of spatial information as well as cartographic data. The Integral Coastal Management and the performance of the corresponding water law necessitate the simultaneous treatment of a mass of information, a great percentage of which is geo-referenced, making the geographic information system an adequate tool for the appropriate use of that information because all data is transformed into cartographic or alphanumeric data.

With the integration of sustainability indicators into the geographic information system it is intended to give the relevant authorities the possibility to use a tool that is useful to evaluate the actions intended to be carried out or just for the analysis of restoration proposals, as well as to analyze and justify the decisions adopted or not adopted to the group of stake holders from the coastal field. 


\section{References}

[1] Almazán, J., (2008), "El Régimen jurídico de los Puertos del Estado. Agenda de Legislación" Edit. E.T.S. Ing. Caminos, C. y P.

[2] Almazán, J., (2006), "El Régimen jurídico de los Puertos del Estado.” Edit. E.T.S. Ing. Caminos, C. y P.

[3] Almazán, J., (2000), "Introducción al diseño de obras de defensa de formas costeras de depósito". Edit. E.T.S. Ing. Caminos, C. y P.

[4] Caturla, J.L. (1988), "Sistema de posicionamiento global (GPS)".MOPU.

[5] Caturla, J.L. (1978), "Determinación de puntos de Laplace". Madrid. Inst. Geográfico Nacional.

[6] Hein, G.W.(1986), "Integrated geodesy: State-of-the art 1986 reference text" in: Sünkel, H.(ed.), Lectures Series in Earth Sciences, Vol. 7, Mathematical and Numerical Techniques in Physical Geodesy, New York.

[7] Hein, G., B. Eissfeller: "The basic equations of carrier phase measurements to the Global Positioning System including general orbit modelling, Schrifttenreihe University Studiengang Munchen, num. 19, 1986.

[8] Almazán, J., (2002), "Posicionamiento y navegación de precisión en 2D y 3D: batimetrías de alta precisión". Edit. E.T.S. Ing. Caminos, C. y P.

[9] Gavala Laborde, J. (1992), "Geología de la Costa y Bahía de Cádiz". Diputación de Cádiz.

[10] Bosque, J. (2006), "Sistemas de información geográfica y localización de instalaciones y equipamientos", Edit. Ra-Ma.

[11] De la Peña, J. (2007), "Guía técnica de estudios litorales: Manual de costas", Edit. Colegio de Ingenieros de Caminos, Canales y Puertos.

[12] Winograd M., 1995, Environmental Indicators for Latin America and the Caribbean: Towards Land Use Sustainability, GASE in collaboration with IICA- GTZ Project, Organization of American States and World Resources Institute, Washington, D.C., 85 pp.

[13] "EU Member State experiences with sustainable development indicators". European Comission, 2004.

[14] Backhaus, R., 2002, "The spatial dimension of landscape sustainability".

[15] "Selected Satellite Images of Our Changing Environment". UNEP 1993.

[16] UNDP, 1994. "Statements and Recommendations from Major International Meetings on Water Resources, Water Supply and Sanitation". UNDP Science, Technology and Private Sector Division. 